\title{
Erratum to: A review on 3D micro-additive manufacturing technologies
}

\author{
Mohammad Vaezi • Hermann Seitz • Shoufeng Yang
}

Published online: 16 April 2013

(C) Springer-Verlag London 2013

\section{Erratum to: Int J Adv Manuf Technol}

\section{DOI 10.1007/s00170-012-4605-2}

In section 6.2.7, Fig. 22 needs to be changed into Fig. 23 (below figure) and the next figures in the paper must be numbered accordingly.

Fig. 23 a Nano-rotor (Igaki et al., 2006) b cell wall cutting tool (Kometani et al., 2006) c filtering tool (Kometani et al., 2006)
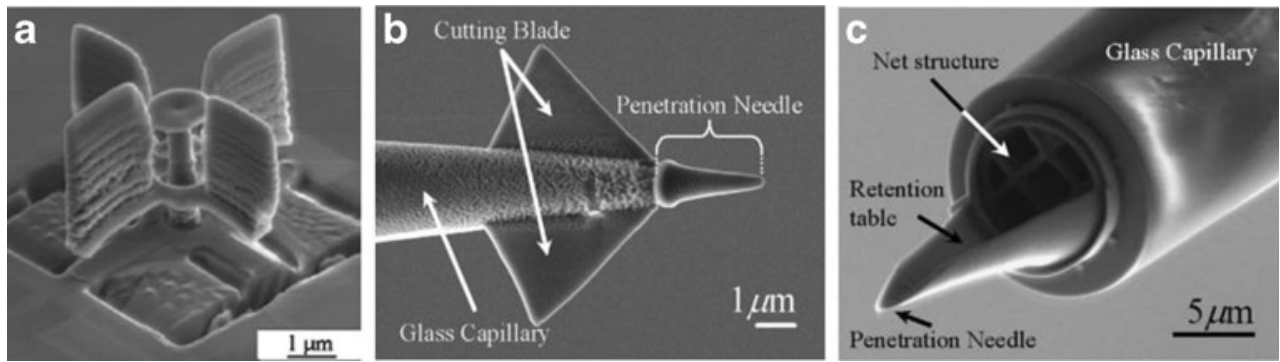

\section{References}

Igaki, J., Kometani, R., Nakamatsu, K., Kanda, K., Haruyama, Y., Ochiai, Y., 2006. Three-dimensional rotor fabrication by focused-ionbeam chemical-vapordeposition. Microelectron. Eng. 33, 1221-1226. Kometani, R., Funabiki, R., Hoshino, T., Kanda, K., Haruyama, Y., Kaito, T., 2006. Cell wall cutting tool and nano-net fabrication by FIB-CVD for subcellular operations and analysis. Microelectron. Eng. 83, 1642-1645.

The online version of the original article can be found at http://dx.doi.org/ 10.1007/s00170-012-4605-2.

M. Vaezi $(\bowtie) \cdot$ S. Yang

Engineering Materials Group, Engineering Sciences,

Faculty of Engineering and the Environment,

University of Southampton, Southampton SO17 1BJ, UK

e-mail: mv1y11@soton.ac.uk

H. Seitz

Fluid Technology and Microfluidics, University of Rostock,

Rostock 18059, Germany 